\title{
A RELAÇÃO ENTRE SUPPOSITIO E SIGNIFICATIO NA SUMMA LOGICAE DE GUILHERME DE OCKHAM
}

Ernesto Perini SANTOS ${ }^{1}$

- RESUMO: Os conceitos de significatio e de suppositio são centrais na semântica ockhamiana; a primeira noção é uma propriedade de termos isolados; a segunda, de termos em proposições. A compreensão da relaçãoentre os dois é muito importante; está em jogo o caráter atomista ou proposicional de sua semântica. A definição de cada um destes termos remete à definição do outro, não sendo possivel determinar a prioridade de um sobre o outro a partir de suas definições. Ambos termos têm excessos em relação ao outro, cobrem casos não cobertos pelo outro. A análise destes excessos permite identificar o termo dominante para explicação de tipos diferentes de fenômenos lingüísticos. Estes tipos de fenômenos são identificados como campos conceituais diferentes, o que permite estabelecer a prioridade de um termo sobre o outro em campos diferentes da semântica.

- PALAVRAS-CHAVE: Significatio; suppositio; semântica.

\section{I}

Qual a relação entre significatio e suppositio em Ockham? A significação é uma propriedade do termo tomado isoladamente. Um signo lingüístico é significativo se traz algo ao conhecimento e pode supor por este algo numa proposição. Esta definição não diz que um termo só é significativo numa proposição, mas que ele deve poder entrar numa proposição, ou é ele mesmo uma proposição. Ser significativo é uma propriedade pré-proposicional do termo. A suposição é uma propriedade proposicional do termo. Um termo só supõe por algo numa proposição. Voltaremos às definições de uma e outra propriedade, mas podemos já ver que definindo uma ou outra como prioritária estamos fazendo uma opção por uma semântica atomista ou proposicional. Com efeito, se dissermos que a propriedade fundamental do termo é a significação, diremos que a semântica fundamenta-se em propriedades do termo tomado isoladamente; inversamente, se fizermos a opção pela suposição, diremos que a semântica interessa-se por propriedades que ocorrem em contextos proposicionais. $\mathrm{O}$

1 Professor de Filosofia - Universidade Federal de Minas Gerais - 31270-900 - Belo Horizonte - MG. 
que está erh jogo não é pouco, procuramos definir qual é a instância fundamental de uma teoria do signo lingüístico, a partir de duas noções básicas. Determinar assim a relação entre significatio e suppositio é uma tarefa importante na compreensão da semântica ockhamiana. Não iremos refazer o rico debate sobre este tema na literatura ockhamiana, os comentadores serão considerados somente na medida em que interessar ao argumento.

Não é possível dizer que uma noção se define em virtude da outra. A definição de signo lingüístico remete à suposição e inversamente. Vamos inicialmente caracterizar a circularidade de definições. Em seguida, veremos os excessos da suposição e da significação e o que os caracteriza. Analisaremos, por fim, a relação entre os dois excessos, que remetem a casos nos quais não há excesso algum. Esta estratégia nos permitirá estabelecer uma relação entre suposição e significação que não é de prioridade de uma sobre a outra, mas de domínios conceituais diferentes.

\section{II}

A definição de "signo lingüístico" faz referência à propriedade de supor:

Compreende-se de outra maneira signo como aquilo que faz vir algo ao conhecimento e está destinado por natureza a supor por este algo ou a ser adicionado a tal tipo de signo numa proposição ... ou o que é destinado a ser composto de tais signos, como a frase. (Ockham, 1989, p.7)²

Propomos a seguinte definição de "signo lingüístico":

Def. signo lingüístico: $x$ é um signo lingüístico se e somente se $x$ traz o conhecimento de $a$, se $x$ é apreendido, a é diferente de $x$ e $x$ pode supor por a numa proposição, fazer parte de uma proposição ou é uma proposição.

Um signo lingüístico significa aquilo por que pode supor. A suposição a que Ockham faz referência aqui é a suposição pessoal (SP); pela definição, um signo supõe por aquilo que significa, o que é próprio da suposição pessoal. A definição da suposição pessoal, por sua vez, faz referência ao significado do termo.

De maneira geral, a suposição é pessoal quando o termo supõe por seu significado... ${ }^{3}$

Propomos a seguinte definição de "suposição pessoal":

Def. suposição pessoal: $x$ supõe em suposição pessoal por a se e somente se $x$ significa a, $x$ ocupa a posição de sujeito ou predicado numa proposição e $x$ fica no lugar de $a$.

2 "Aliter accipitur signum pro illo quod aliquid facit in cognitionem venire et natum est pro illo supponere vel tali addi in propositione ... vel quod natum est componi ex talibus, cuiusmodi est oratio." Somme de Logique doravante será citada como $S L$.

3 "Suppositio personalis, universaliter, est illa quando terminus supponit pro suo significato...", (SL, p.201). 
As definições são circulares, não é possivel dizer, a partir das definições, qual a noção prioritária, ${ }^{4}$ como parece pretender Loux (1979, p.420). Deve-se observar, com Panaccio, que esta circularidade de definições não é tão grave quanto o seria numa construção axiomática (1984). Na ordem da definição, como diz ainda Panaccio, não há prioridade. Mas não há só circularidade de definições entre significatio e suppositio, há também excessos num e noutro caso. Um termo pode supor por algo que não significa e significar algo por que não supõe. Nosso próximo passo será examinar estes excessos, para esclarecer a relação entre estes dois conceitos na Summa logicae de Ockham.

\section{III}

A suposição excede a significação quando um termo em suposição simples (SS) ${ }^{5}$ ou em suposição material $(\mathrm{SM})^{6}$ supõe por algo que não significa. Estes casos podem ser identificados genericamente à noção contemporânea de menção, em oposição ao uso, que se identifica com a suposição pessoal. Nos dois casos, os termos são tomados não significativamente. Quais são as condições de tal excesso? Inicialmente, as condições gerais da suposição. Podemos definir "suposição" sem considerar seus diferentes modos, da seguinte forma:

Def. Suposição: um termo $x$ supõe por a se e somente se $x$ está na posição de sujeito ou predicado numa proposição e $x$ fica no lugar de $a$.

As condições da suposição, independentes de seu modo, são:

a) o termo estar numa proposição;

b) o termo estar em posição de sujeito ou predicado;

c) o termo ficar no lugar de alguma coisa.

A condição (a) restringe a propriedade de suposição em relação à significação, pois um termo é significante independentemente de sua inserção proposicional, o que não ocorre com a suposição. A condição (b) refere-se a "termo" no sentido primeiro do Capítulo 2:

O nome "termo" compreende-se de três modos. Num sentido, chama-se "termo" tudo aquilo que pode ser a cópula ou o extremo de uma proposição categórica, a saber o sujeito ou o predicado ou ainda uma determinação de um extremo ou de um verbo. ${ }^{\text {? }}$

4 "The conclusion of this is that, according to the order of definition, neither the notion of signification nor that of supposition is logically prior to the other one in Ockham's semantics" (Panaccio, 1984, p.67).

5 "Suppositio simplex est quando terminus supponit pro intentione animae, sed non tenetur significative...", (SL, p.201).

6 "Suppositio est materialis est quando terminus non supponit significative, sed supponit vel pro voce vel pro scipto" (SL, p.202)

7 'Est autem sciendum quod hoc nomen 'terminus' tripliciter accipitur. Uno modo vocatur terminus omne illud quod potest esse copula vele extremum propositionis categoricae, subiectum videlicet vel praedicatum, vel etiam determinatio extremi vel verbi'" $(S L$, p.8). 
Este sentido inclui termos simples e complexos, ${ }^{8}$ tomados significativamente ou não. ${ }^{9}$ Em uma frase como "as moscas engraçadas chegaram", o termo que supõe é "as moscas engraçadas", não apenas "moscas". Na frase "'a mesa é verde' é uma frase", 'a mesa é verde' está em SS e é um termo apenas no sentido acima apontado, já que é um termo complexo tomado não significativamente. O excesso está indicado no segundo item, já que termos supõem por algo que não podem significar se não são tomados significativamente. O item (c) é um termo primitivo, que identificamos quando estão realizadas as outras condições da suposição. ${ }^{10} \mathrm{O}$ excesso da suposição em relação à significação está portanto em termos (no primeiro sentido do Capítulo 2) em contextos proposicionais tomados não significativamente. Só há termos tomados não significativamente em contextos proposicionais. Um termo só pode estar em SM ou em SS num contexto proposicional, porque em tais casos deve haver um termo em suposição SP no outro extremo da proposição. ${ }^{11}$ Para que um termo suponha em SS ou SM, é necessário que o outro extremo da proposição signifique o conceito (SS), ou o som vocal ou a marca escrita (SM) pelo que vai supor o termo tomado não significativamente. No exemplo acima, "a mesa é verde" está em suposição simples porque é significada como frase pelo predicado "é uma frase". A suposição é um conceito que é mais amplo que o de significação se consideramos os termos em proposições.

Quando a significação excede a suposição? Um termo significa de maneira secundária aquilo por que não pode supor, o que não depende de um contexto proposicional. "Branco" remete, de maneira secundária, à brancura, mesmo fora de uma proposição. O que determina o excesso da significação neste caso? O termo ter mais de um significado, isto é, significar de mais de um modo aquilo que significa. Termos conotativos são justamente termos que significam aquilo que significam de mais de um modo, ${ }^{12}$ em oposição a termos absolutos. ${ }^{13}$ Há uma primeira oposição em relação à suposição: não interessa aqui a inserção proposicional do termo. Esta oposição aponta para uma outra, a do sentido de "termo". No caso anterior, vimos como "termo" é tomado no sentido da primeira definição do Capítulo 2. Neste caso, "termo" é tomado no sentido da segunda definição deste mesmo Capítulo. É termo todo elemento incomplexo, distinto da proposição. É neste sentido de "termo" que podemos falar de termos conotativos e absolutos. Ockham mesmo diz que é neste sentido que

8 "Et isto modo etiam una propositio potest esse terminus, sicut potest esse pars propositionis", (Ibidem). O fato de poder ser um elemento complexo opõe este sentido de "termo" ao segundo sentido do Capítulo 2: "Aliter accipitur hoc nomen 'terminus' secundum quod distinguitur contra orationem; et sic omne incomplexum vocatur terminus", (Ibidem).

9 Termos neste sentido podem supor se tomados não significativamente, contrariamente ao terceiro sentıdo do Capitulo 2: "Tertio modo accipitur 'terminus' praecise et magis stricte pro illo quos significative sumptum potest esse subiectum vel praedicatum propositionis" (Ibidem).

10 Supomos aqui asserções verdadeiras, o que não influi no nosso argumento.

11 "Sed terminus non in omni propositione potest habere suppositionem simplicem vel materialem, sed tunc tantum quando terminus talis comparatur alteri extremo quod respicit intentionem animae vel vocem vel scriptum", (SL, p.204).

12 "Nomen autem connotativum est illud quod significat aliquid primario et aliquid secundario", (SL, p.16).

13 "Nomina mere absoluta sunt illa quae non significant aliquid principaliter et aliud vel idem secundario, sed quidquid significatur per illud nomen, aeque primo significatur..."(Ibidem). 
"termo" é tomado na Summa. ${ }^{14}$ São conotativos termos simples, um termo complexo não é dito conotativo. É claro que, sendo uma propriedade do termo independente do contexto proposicional, o termo aqui não pode ser tomado não significativamente, o que só ocorre numa proposição.

A rigor, não se deveria falar em "ser tomado" de modo algum, já que um termo só é tomado de tal ou tal modo em uma proposição. Convém esclarecer o sentido de "ser tomado significativamente". Um termo está em SP quando é tomado significativamente, e isto a distingue dos outros tipos de suposição. Termos tomados em SP e apenas termos tomados em SP supõem por seu significado. Ora, termos em SP e apenas eles são tomados significativamente, assim, "supor por seu significado" e "ser tomado significativamente" são equivalentes, nos dois casos identificamos os termos em SP. ${ }^{15}$ Assim, se consideramos o significado de um termo, tratamos daquilo porque supõe se tomado significativamente. É claro que, tratando do excesso da significação sobre a suposição, um termo significa algo por que supõe e algo por que não pode supor.

\section{IV}

Ora, num e noutro caso a possibilidade dos excessos refere-se a um termo no qual não há excesso, seja um termo em SP, seja um termo que não significa nada por que não possa supor. Um termo que supõe em SS ou SM supõe por aquilo que não significa e esta possibilidade é ela mesma coordenada por um termo em SP, que supõe por aquilo que significa. A possibilidade da suposição exceder a significação refere-se a um termo cujos supposita identificam-se àquilo que significa.

Termos que significam algo por que não supõem são termos que têm uma significação primária e uma significação secundária. Eles significam aquilo que significam os termos principais a partir dos quais foram impostos, pelo que não podem supor. Esta referência ao significado principal aparece no Capítulo 33 de SL, no terceiro sentido de "significar":

Compreende-se "significar" de outro modo quando se diz que é significado aquilo a partir do que o som vocal foi imposto ou aquilo que é significado de modo primário pelo conceito principal ou pelo som vocal principal. Deste modo, dizemos que "branco" significa a brancura, porque "brancura" significa a brancura, pelo que contudo o signo "branco" não supõe. ${ }^{16}$

14 "Visa aequivocatione istius nominis 'terminus' prosequendum est de divisionibus termini incomplexi" (SL, p.10). Na verdade, ao dizer que a suposição trabalha com outro sentido de termo, dizemos que Ockham não usa o mesmo sentido de "termo" ao longo de toda Summa. Parece-nos, contudo, que ele usa o sentido 2 de "termo" nos capítulos que se seguem a esta declaração, mesmo se, para sabê-lo, seja preciso ver qual sentido é operacional.

15 Ockham diz que não basta dizer que um termo supõe por seu significado para estar suposição pessoal, é preciso dizer que é tomado significativamente. Esta precisão, diz Biard, deve-se aos diferentes tipos de significado (Cf. 1989, p.80), mas pode ser desconsiderada; alguns importantes comentadores o fazem: cf. Loux, 1974, p.24; Karger, 1984, p.90; Adams, 1987, p.346; Panaccio, 1991, p.37. Boehner acredita ser necessário a precisão, mas sua explicação parece-nos redundante (cf. 1992, p.237).

16 'Aliter accipitur 'significare' quando illud dicitur significari a quo ipsa vox imponitur vel illud quod primo modo significatur per conceptum principalem vel vocem principalem. Et sic dicimus quod 'album' significat albedinem, 
Não entraremos aqui na discussão deste trecho, que envolve uma relação entre signos nem sempre considerada pelos comentadores. Basta notar como "branco" remete à brancura, que não significa de modo primário, pelo que portanto não pode supor. Por que "branco" significa a brancura neste sentido de "significar"? Porque significa aquilo a partir do que foi imposto. "Branco" remete justamente àquilo que é significado por "brancura", que, sendo um termo absoluto, supõe por aquilo que significa. É justamente isto que queríamos estabelecer. Um e outro excesso remetem a situações nas quais não há excessos, ou seja, a termos em SP ou a termos absolutos.

Vimos no início do texto como os casos principais da suposição (SP), que determina a possibilidade do desvio da suposição, e da significação (termos absolutos), a partir do qual são impostos os termos cuja significação excede a suposição, remetem um ao outro, ou seja, não saímos da circularidade das definições.

A passagem pelos excessos nos indica, contudo, campos diferentes dominados ou pela suposição ou pela significação. A suposição é o conceito central no nível proposicional.

Inicialmente, Ockham quer tomar a noção de referência padrão ou suppositio pessoal como conceitualmente anterior à noção de sentido ou significatio; ele quer dizer que não há relação palavra-mundo semanticamente mais fundamental do que aquelas envolvidas no funcionamento de um termo como artifício de referência (referring device) em contextos proposicionais normais. (Loux, 1979, p.423) $)^{17}$

Considerada no nível proposicional, a linguagem tem como conceito central a suposição. O sentido de "termo" usado na definição de "suposição" considera a linguagem já formada, já constituída em proposições; o termo aí é o resultado da consideração de sua função sintática em proposições. Se toda linguagem for proposicional, a suposição é o conceito central.

Mas toda linguagem é proposicional em Ockham?

A complexidade desta relação entre significação e suposição manifesta-se no aspecto teleológico dos enunciados que concernem ao signo e à significação. O signo está destinado a supor, ele é definido por esta aptidão ao mesmo tempo em que ele é colocado como anterior. Resumindo, a significação é colocada como suposição potencial. (Biard, 1989, p.93) ${ }^{18}$

quia 'albedo' significat albedinem, pro qua tamen albedine non supponit hoc signum 'album'" (SL, p.100).

17 O segundo ponto de que Loux trata, que entender o sentido de um termo "is rather to be understood in terms of recognitional skills or identificatory abilities" (p.423), não se deve à prioridade da suposição sobre a significação, mas ao nominalismo de Ockham (Cf. Panaccio, 1984, p.63).

18 A interpretação de Biard, assim como a De Rijk (1982), favorece a suppositio, às expensas da significatio. Em ambos os casos, a abordagem é mais histórica. Parece claro, tanto em De Rijk quanto em Biard (1989), que a evolução da lógica medieval parte da idéia de significação atemporal e independente de contexto de um termo em direção à idéia de suposição, e Ockham é, neste como noutros pontos, fundamental artífice da mudança. Isto não significa, no entanto, nem que Ockham tenha realizado toda a passagem na sua obra, nem que devamos projetar evoluções que se realizaram plenamente depois dele e eventualmente a partir dele como acabadas na 
O signo assim definido é o signo lingüístico. Ele só é signo lingüístico na medida em que pode entrar numa proposição, que é aquilo que o diferencia de outros tipos de signo. O fato de ser destinado a fazer parte de uma proposição, supondo ou não, distingue "signo lingüístico" de "signo" no Capítulo 1 de SL.

Um signo lingüístico que pode entrar numa proposição não está contudo necessariamente numa proposição. É difícil justificar esta posição na Summa, porque um signo não está num contexto proposicional se considerarmos sua gênese a partir da experiência, que não é tematizada na Summa. Assim, na Ordinatio, que trata da teoria do conhecimento, podemos ler:

todo ato judicativo pressupõe na mesma potência o conhecimento incomplexo dos termos, porque pressupõe o ato de apreensão, e o ato de apreensão a respeito de um certo complexo pressupõe o conhecimento incomplexo dos termos... (Ockham, 1967, p.21) $)^{19}$

Esta passagem refere-se a termos mentais, mas a propriedade de ser significativo fora de contextos proposicionais pode ser transferida a termos convencionais a eles associados. Do ponto de vista da origem da significação, a linguagem não é necessariamente proposicional, ou antes os termos não estão necessariamente em proposições. Ao contrário, a apreensão de complexos (proposições) pressupõe a apreensão de incomplexos (termos), que são, portanto, anteriores e podem existir no intelecto sem as proposições. Ora, deste ponto de vista, não a suposição, mas a significação, é prioritária.

Considerando a linguagem um conjunto de proposições, a suposição é o conceito principal; considerando a linguagem do ponto de vista do surgimento da significação a partir da experiência, isto é, a partir de uma teoria do conhecimento, a significação é o conceito principal. É interessante observar como ambos aparecem no texto da Summa, no qual poderíamos esperar que apenas a suposição dominasse. Os dois excessos encontrados indicam precisamente que os dois conceitos centrais da semântica ockhamiana são alternadamente dominantes no texto mesmo da Summa e em campos bem precisos.

Há uma mudança do sentido de "termo", o que é um fato importante quando se trata justamente da lógica dos termos, o tema da primeira parte da Summa. Os fatos relevantes também não são os mesmos. Não é a mesma coisa, com efeito, referir-se à origem do significado de um termo na experiência e referir-se à organização de termos numa proposição. Há uma mudança de ponto de vista, ou seja, os fatos considerados relevantes num contexto não o são em outro. Não interessa saber 0 termo mental a partir do qual um termo convencional foi imposto para saber em que tipo de suposição está. Inversamente, a inserção proposicional de um termo não é relevante se vamos considerar a imposição de um termo.

sua obra, mesmo que elas se encontrem aí como tendência ou in nuce.

19 "quod omnis actus iudicativus praesupponit in eadem potentia notitiam incomplexam terminorum, quia presupponit actum aprehensivum. Et actus aprehensivus respectu alicuius complexi presupponit notitiam incomplexam terminorum..."; este texto é citado em Panaccio, 1984, p.68. 
Se podemos definir onde cada noção é dominante, não podemos separá-las de maneira estanque. Da linguagem já organizada em proposições, somos remetidos à relação entre termos que se explicam a partir da origem da significação. E, inversamente, o signo lingüístico, mesmo quando definido antes de sua inserção proposicional, define-se como lingüístico pela possibilidade da inserção proposicional. Esta é a circularidade de definições. Há uma outra circularidade, que nos remete de um e outro excessos a casos nos quais não há excesso.

Sugerimos assim que existem na primeira parte da Summa dois domínios conceituais distintos, que consideram aspectos diferentes da linguagem e usam diferentes sentidos de "termo". Num destes domínios, onde "termo" é definido como elemento simples e a linguagem é considerada a partir de sua origem na experiência, a noção de significatio é mais importante. No outro domínio, onde "termo" é definido a partir de sua função sintática e consideram-se as relações entre os signos, a noção de suppositio é prioritária. Devemos estar atentos às ferramentas conceituais usadas em cada caso para entender que noção é dominante em cada momento e que aspectos da linguagem são relevantes. Esta é uma distinção de método, diríamos hoje, para abordar aspectos diferentes da teoria do signo lingüístico. Não são abordagens contraditórias, mas complementares. Há uma duplicidade de método que procura se adequar à complexidade dos fenômenos abordados. Se esta duplicidade não é tematizada por Ockham, ela é pelo menos praticada, como acreditamos ter mostrado parcialmente neste texto.

SANTOS, E. P. Suppositio and significatio in Ockham's Summa Logicae. Trans/Form/Ação (São Paulo), v.19, p.195-203, 1996.

- ABSTRACT: Significatio and suppositio are central notions in Ockham's semantics; the former is propriety of isolated terms, the later, of terms in propositional contexts. Understanding the relation between both notions is important to determine the atomistic or propositonal character of Ockham's semantics. The definition of each term refers to the other, not allowing any prionity of one of them. Both terms exceed one another, covering cases which are outside the scope the other. We identify, through the analysis of this excess the dominant term for the explanation of different kinds of linguistic phenomena. These different kinds of phenomena are identified with two different conceptual fields, each term (suppositio and significatio) being dominant in one field.

- KEYWORDS: Significatio; suppositio; semantics.

\section{Referências bibliográficas}

ADAMS, M. William Ockham. Notre Dame: University of Notre Dame, 1987.

BIARD, J. Logiques et théorie du signe au XIV siècle. Paris: Vrin, 1989.

BOEHNER, P.Collected Articles on Ockham. St. Bonaventure: The Franciscan Institute, 1992 (1958). 
DE RIJK, L. M. The Origins of the Theory of the Properties of Terms. In: KRETZMANN et al. (Ed.) The Cambridge History of Later Medieval Philosophy. Cambridge: Cambridge University Press, 1982. p.161-73.

KARGER, E. Modes of personal supposition: the purpose and usefulness of the doctrine within Ockham's logic. Franciscan Studies, n.44, p.87-106, 1984.

LOUX, M. de. Ockham on Generality. In: OCKHAM, G. de. Ockham's Theory of Terms, Part 1 of the Summa Logicae. Trad. e introd. por M. J. Loux. Notre Dame: University of Notre Dame Press, 1974. p.23-46.

Significatio and Suppositio: Reflections on Ockham's Semantics. The New Scholaticism, v.53, p.407-27, 1979.

OCKHAM, G. de. Scriptum in Librum Primum Sententiarum sive Ordinatio, Prologus et Distinctio prima, Opera Theologica I. Ed. Gedeon Gál. St. Bonaventure: Ed. Instituti Fransciscani S. Bonaventure, 1967. (Ordinatio).

Somme de logique. Trad. e notas J. Biard. Ed. bilingue. Mauvezin: TransEuropRepress, 1989.

PANACCIO, C. Propositionalism and atomism in Ockham's Semantics. Franciscan Studies, n.44, p.61-70, 1984.

. Les mots: les concepts et les choses. Paris: Bellarmin, Vrin, 1991.

SPADE, P. V. Ockham's distinctions between absolute and connotative terms. Vivarium, v.13, n.1, p.55-76, 1975. 